\title{
De entendidas e sapatonas: socializações lésbicas e masculinidades em um bar do Rio de Janeiro"
}

\author{
Andrea Lacombe
}

\begin{abstract}
Resumo
Este artigo apresenta os modos de socialização de um grupo de mulheres lésbicas masculinas em um bar do centro do Rio de Janeiro. Através da explicitação das autodenominações e das performances corporais, tento desvendar modos alternativos de construção de masculinidades que tem como suporte o corpo das mulheres e não dos homens. Por sua vez, essas performances dão espaço para a discussão dos modos em que as categorias binárias de homem/mulher e masculino/feminino se desmancham na cotidianidade do campo.
\end{abstract}

Palavras-chave: Masculinidades, Lesbianismo, Estudos Queer, Estudos de Gênero.

\footnotetext{
* Recebido para publicação em fevereiro de 2006, aceito em maio de 2006. O presente texto baseia-se em parte da minha dissertação de mestrado, cf. Lacombe, 2005.

** Doutoranda, PPGAS/MN/UFRJ. andrealacombe@yahoo.com.br
} 
De entendidas e sapatonas

On Entendidas and Sapatonas:

Lesbian Socialization and Masculinity in a Bar in Rio de Janeiro

\begin{abstract}
This article presents the socialization of a group of masculine lesbian women in a bar in Rio de Janeiro's downtown. Though the explicitation of their self-denomination and body performances, I try to unveil alternative ways of masculinity construction based on women's bodies instead of on those of men. In addition, these performances open (a space for) the discussion of how the binary categories man/woman and masculine/feminine vanish in fieldwork.
\end{abstract}

Keywords: Masculinities, Lesbianism, Queer Studies, Gender Studies. 
Centro da cidade do Rio de Janeiro. Bar Flôr do André. Poderia ser um bar qualquer, um boteco localizado em uma área populosa e popular do Rio, enfeitado com umas poucas mesas e cadeiras de plástico, freqüentado por homens em procura cerveja ou cachaça para acompanhar a conversa com amigos depois do trabalho. Entretanto, o Flôr do André tem uma particularidade que será o foco de análise neste texto: a freguesia está formada por mulheres que gostam de outras mulheres e preferem relegar aos homens, antigos donos do espaço, a um cantinho esquecido do bar.

O Flôr do André aparece então como um botequim carioca localizado na Rua André Cavalcanti, que a simples vista reúne quase todas as características de um estabelecimento de bebidas desse tipo ${ }^{1}$, com freguesia regular de alta freqüência e prolongado tempo de permanência. A venda de bebidas alcoólicas é a principal atividade do lugar; a clientela é composta de pessoas que moram nas proximidades, cuja renda é baixa e o nível de instrução não ultrapassa, em sua maioria, o segundo grau. Porém, o fato de serem mulheres, e não homens, que freqüentam o local constitui um diferencial importante que redesenha até o modo de nomear o lugar. Desse modo, a palavra bar ganha força, desterrando quase a de boteco que aparece só na boca de alguns antigos fregueses que ainda freqüentam o lugar. Em torno desses dados, comecei a considerar o Flôr do André como uma hibridação entre bar e boteco, fruto da freguesia - mulheres, na sua maioria, lésbicas - e das relações que, a partir dela, se estabelecem. A mistura resultante das particularidades sociológicas - características de um botequim com um público que, além de relações homossociais, evidenciam relações homoeróticas - cria

\footnotetext{
1 Segundo Luiz Antônio Machado da Silva (1969:160-182), o botequim é uma instituição freqüentada por homens trabalhadores de camadas baixas localizados geralmente perto da entrada das favelas ou em regiões de baixa renda da cidade. Por outro lado, a duração e a intensidade da permanência no local é marcante para distingui-lo: tem uma freguesia fixa. "A assiduidade dos fregueses é de tal ordem, que em muitos casos o botequim depende dele para sobreviver".
} 
De entendidas e sapatonas

uma maneira diversa de pensar um local de bebidas, freqüentado por pessoas de baixa renda no centro do Rio de Janeiro, e singulariza a sua análise.

Note-se, porém, que não utilizo em lugar nenhum a expressão $\mathrm{GLS}^{2}$, que poderia ser pensada como específica para um espaço com essas características de socialização. Essa nomeação apareceu apenas uma vez ao longo do trabalho de campo e foi utilizada por Greg - um jovem holandês - em resposta à minha pergunta sobre as razões pelas quais gostava de freqüentar o lugar. Entretanto, as freguesas recusaram explicitamente a utilização desta locução para definir o bar, estabelecendo uma diferenciação entre "boite gls" e "bar familiar" e qualificando o Flôr do André com a segunda expressão. Por que esse empenho em se diferenciar de um espaço GLS?

Como as tabernas de Pardais, pesquisadas por Miguel Vale de Almeida (1995) que dão lugar ao café como novo centro de socialização, em continuidade com as interações e funções que ligam taberna e tradição, pode-se pensar na mudança do Flôr do André de boteco para bar. Mesmo conservando o papel homossocializante $e^{3}$ que caracteriza o boteco na literatura sociológica brasileira, são as mulheres, $e$ não os homens, que interpretam esse papel. Assim, no Flôr do André, os relacionamentos que se constroem a partir de vivências comuns

2 Sigla utilizada no Brasil para identificar lugares específicos de socialização de Gays e Lésbicas; a letra S corresponde a "Simpatizantes", como um modo de expressar a abertura a pessoas que, mesmo não praticando atividades homoeróticas, freqüentam aqueles espaços. Esta sigla também é utilizada por gays e lésbicas como modo de autodefinição. Em relação aos grupos de ativismo, a sigla tem começado a mudar para GLBT (gays, lésbicas, bissexuais e transgêneros) por considerá-la politicamente correta, incluindo outras minorias além de gays e lésbicas, reconhecidos pelo ativismo internacional como parte da causa pela defesa do reconhecimento dos direitos das diferenças sexuais.

3 Utilizo a denominação "homossocialização", "homossociabilidade" ou "homossocial" para me referir àqueles tipos de relacionamento social que se estabelecem entre indivíduos do mesmo sexo. Cf. Kosofsky, 1985; Vale de Almeida, 1995; Blázquez, 2004. 
ou completamente diferenciadas conformam as particularidades desse lugar, que aparece como um boteco de mulheres, entendidas, sapatonas, em convívio com homens heterossexuais onde as performances de masculinidade e de feminidade se misturam e se confundem.

Algumas dessas particularidades se visibilizam discursivamente nos modos de autorreferencialidades presentes no lugar.

\section{Entendida? do babado? sapatona? lésbica? Denominações e autorreferencialidades}

- Oh, Martinha, me explica porque vocês usam a palavra "entendida".

- Olha, de onde vem eu não sei, só o que eu não gosto é a palavra sapatão; que sapatão é quem tem sapato grande, não é? Foi o Chacrinha que começou a usá-la acho... mas a palavra entendida ficou mas suave... de onde é que vem eu não sei, entendida é quem entende, quem entende o outro, pra mim a explicação é essa.

- Entender o quê??

- Que eu te entendo, que eu entendo você.

- Eu acho que entendida seria que entende os héteros [sexuais] e entende a própria mulher que ela gosta, entendeu? Eu acho que isso é a palavra entendida, porque não desrespeita a opinião dos heterossexuais e então entende as meninas, entendeu? [acrescenta Magnata, outra das freguezas do lugar]. ${ }^{4}$

No Flôr do André, a palavra lésbica não faz parte do contexto discursivo. Os modos de (auto)denominação dispensam esse vocábulo que aparece distante e sem força semântica. Entendida, como auto-referencial, ou simplesmente mulher, quando são os outros fregueses os que falam são os termos mais

4 Entrevista realizada no bar Flôr do André durante minha pesquisa de campo (maio- setembro de 2004). 
De entendidas e sapatonas

utilizados no lugar, entretanto, a expressão ser do babado e a palavra sapatona ou sapatão também aparecem, porém, com menos freqüencia.

Entender se transforma em um modo de cumplicidade, de compartir um segredo que, apesar de público, não implica a ausência de intimidade. Ser do babado, por sua vez, estabelece um sentido de pertença a um universo particular, neste caso, um universo de homoerotismo. Por outro lado, o termo sapatona ou sapatão, denotando características de masculinidade extrema, é usado geralmente pelas freguesas mais velhas e masculinas como auto-referência ou pelas mais jovens quando tentam menosprezar umas às outras em uma conversa (não necessariamente por motivo de briga).

Entretanto, existe na teoria queer um termo específico para denominar as lésbicas masculinas: butch. Este é usado por Judith Halberstam (seguindo Gayle Rubin) para definir "mulheres que sentem-se mais confortáveis com estilos, códigos e identidades genericamente masculinas do que com àqueles femininos". ${ }^{5} \mathrm{~A}$ expressão lesbian masculinity é a escolhida pela autora para se referir a "mulheres que performam sua masculinidade em relações reconhecidas como lésbicas". ${ }^{6}$ Eu não utilizarei exatamente esta terminologia por considerá-la discurso nativo norte-americano, mesmo que esteja espalhada como categoria entre os queer studies, nem a desconhecerei porque possibilita explicitar através da discursividade a explosão das categorias de sexo e gênero. Acho melhor falar em masculinidades de mulheres, já que as freguesas do Flôr do André continuam a se identificar como mulheres entendidas, desusando a palavra lésbica $e$ desconhecendo o termo butch, por mais que com essas práticas colaborem para quebrar a binariedade compulsória que implica a utilização dos termos homem e mulher.

\footnotetext{
5 "women who are more comfortable whith masculine gender codes, styles or identities than with feminine ones" (Halberstam, 1998:120).

6 "women who perform their masculinity whithin what are recognizably lesbian relations" (Halberstam, 1998:120).
} 
Considero importante destacar a diferença de terminologia que existe com o discurso ativista local onde o politicamente correto parece ser o uso das palavras lésbica ou homossexual feminina, justamente aqueles termos que perdem carga semântica nas falas do Flôr do André. ${ }^{7}$ A meu ver, esta ação denota um afastamento dos usos do cotidiano ou uma desagregação do discurso d@s representad@s nos modos de construir a imagem do sujeito político. Acho politicamente necessária a inclusão dessas falas, porque é através delas que os sujeitos se reconhecem e se auto-identificam. Mesmo assim é preciso lembrar o caráter histórico e contingente das palavras, razão pela qual seus usos também devem ser revistados permanentemente para não deixar de fora aquel@s que esperam ser representad@s. Falar em categorias fixas para representar minorias resulta num oximorom, se levamos em conta que as minorias são contingentes, mutáveis, instáveis, sempre concebidas em relação ao centro. Talvez, o uso das nonce taxonomies ${ }^{8}$, de Eve K. Sedgwick, seja uma saída,

\footnotetext{
7 A definição que Jacqueline de Oliveira Muniz faz sobre o fato de entender em detrimento daquele explicitado por Fry e MacRae lança uma luz sobre este assunto. Para o mundo gay, explica, "parece mais relevante se um virtual parceiro pode 'entender', 'pegar', 'sair', 'topar', ou 'fazer' com alguém do mesmo sexo do que se ele é 'realmente' homossexual". Esta forma de pensar a palavra entendid@ desconstrói a idéia de uma substância ou um estrato predeterminado que dá origem e sustento à homossexualidade. Desconstrói também a idéia de uma possível cultura ou sub-cultura homossexual. Cf. Muniz de Oliveira, 1992; Fry e MacRae, 1985.

8 Trata-se de "taxonomias ad hoc", que não organizam seres ou práticas preexistentes em função de aspectos "naturais", porque os elementos a classificar e seus traços constitutivos são estabelecidos a partir de categorias orientadas para tal fim. Por exemplo, pela heterossexualidade normativa e suas necessidades classificatórias. A distinção entre práticas "normais" e "perversas" se edifica no contexto de uma taxonomia construída com o propósito mesmo da distinção. A partir desta lógica, pode-se pensar em categorias criadas, conjuntural $e$ contingentemente, com um propósito determinado, mas que podem ser desmontadas e, assim, perderem sua utilidade, desvendando a suposta universalidade de categorias como heterossexualidade, gênero ou sexo. Essa operação discursiva é usada por Judith Halberstam (1998:9), ao se referir a "masculinidades femininas" (female masculinity).
} 
De entendidas e sapatonas

sempre temporária, para pensar a política no mundo de hoje; e a substituição da idéia de minoria pela de multidão ${ }^{9}$, no discurso político, seja mais acertada para falar de grupos nos quais a desidentificação com um mundo heteronormado parece ser a única similitude.

Pensada a partir desta perspectiva, me parece difícil acreditar na existência de uma "cultura GLS" ou alguma coisa parecida. O fato de compartir uma orientação sexual não traz como correlato direto compartir visões de mundo. Talvez seja factível argumentar a partir de pontos de referência próximos daqueles que estão nas margens de sociedades heteronormadas, que pressupõem comportamentos heterossexuais. Entretanto, os entrecruzamentos que formam um sujeito se (re)configuram em uma escala espaço-temporal que parece diluir a possibilidade de criar compartimentos estanques para situar os indivíduos, em um mundo onde as grandes classificações modernas de raça, classe, sexo e gênero parecem não achar mais espaço. "A fabricação antropológica de sistemas culturais é produto da representação da diferença no discurso da homogeneidade". ${ }^{10}$

\footnotetext{
9 Beatriz Preciado propõe a utilização da noção ou categoria de multidões (multitudes) como modo de substituir a idéia de minorias sexuais para conseguir estruturar um sujeito politicamente plausível. "Não há uma diferença sexual, mas uma multidão de diferenças, uma transversalidade de relações de poder, uma diversidade das potencias de vida. Essas diferenças não são 'representáveis' porque são 'monstruosas' e colocam em questão tanto os regimes de representação política per se, quanto os sistemas de produção de saber científico dos "normais" [Il y n'a pas de différence sexuelle, mais une multitude de différences, une transversale des rapports de pouvoir, une diversité de puissances de vie. Ces différences ne sont pas 'représentables' car elles sont 'monstrueses' et remettent en question par là même les régimes de representation politique, mais aussis les systèmes de production de savoir scientifique des 'normeaux'] (Preciado, 2003:25).

10 "The anthropological fabrication of cultural systems is a product of the representation of difference in the discourse of homogeneity" (Ingold, 1993:218).
} 
Andrea Lacombe

Vejamos agora como esses entrecruzamentos conspiram, configurando novas percepções da masculinidade nos corpos que apareceriam como "errados".

"Pochete é crachá de sapatão": masculinidades de mulheres

Ao quê me refiro quando falo em masculinidades de mulheres?

Existe uma certa bibliografia inserida nos estudos queer que analisa aquelas mulheres que, sem deixar de sê-lo, incorporam comportamentos tidos como exclusivos dos homens. ${ }^{11}$ Mesmo assim, o ponto de partida deve ser colocado em um patamar anterior: o fato de explicitar a possibilidade de uma masculinidade de mulheres implica previamente desconsiderar a masculinidade como incindível da estrutura biológica do homem e desenhá-la como uma ficção que se constrói performática e socialmente. No seu livro Female Masculinity, Judith Halberstam desenvolve seu argumento com relação a o que ela chama de masculinidades sem homens, numa tentativa de desobrigar a masculinidade de habitar só o corpo do homem, historicizando-a, desconstruindo-a e levantado a questão de ser uma categoria teórica mais do que uma concepção da natureza. Assim, a autora estrutura a masculinidade de mulheres como uma alternativa àquela considerada hegemônica (a dos homens brancos, heterossexuais, de classe média, de países centrais). Nessa mesma linha crítica, podemos mencionar Dislocating masculinity, coletânea organizada por Andrea Cornwall e Nancy Lindisfarne (1994), que revê o sentido unívoco da masculinidade, lançando uma luz sobre os diferentes modos em que ela se apresenta na socialização. Esta

\footnotetext{
${ }^{11}$ Sem sentir-se um homem dentro do corpo de uma mulher. Isto já corresponderia ao âmbito da transgeneridade em que a procura é por mudar de gênero performatizando um homem (a versão masculina de um travesti) ou, mais radicalmente, a transexualidade, onde a mudança também é do corpo através da incorporação de hormônios masculinos (testosterona) e intervenções cirúrgicas.
} 
De entendidas e sapatonas

coletânea está integrada por artigos que analisam a masculinidade em diferentes sociedades, tanto em homens como em mulheres.

Neste ponto, gostaria de apresentar uma situação. Em uma viagem de férias que realizei no ano de 2001 ao Rio de Janeiro, escutei de uma irônica amiga uma expressão que só consegui compreender em toda sua dimensão num baile de forró para o qual fui convidada pelas freguesas do Flôr do André em 2004. Na ocasião da minha viagem, eu costumava usar pochete porque não gostava de levar uma bolsa que me incomodasse na mão ou me atrapalhasse para tirar fotos e essas coisas que fazemos na performance do turismo. Um dia, antes de sair da casa de minha amiga Silvina, ela, olhando-me da cabeça aos pés, deteve a mirada na pochete que estava pendurada na minha cintura e, sem mais, me espetou com aquela frase: "pochete é crachá de sapatão". Várias foram as explicações que apareceram na mesa do bar para aquela expressão, todas elas em referência a uma induvidosa masculinidade atribuída às lésbicas: é um acessório mais usado pelos homens do que pelas mulheres, é mais confortável do que elegante, não dá para guardar muita coisa (com relação ao estereótipo criado sobre a profusão de objetos que podem ser encontrados numa bolsa de mulher), não fica legal com saia ou vestido... Mesmo assim, havia naquela expressão algum aditamento que ainda estava fora do nosso alcance.

Em junho de 2004, durante o trabalho de campo que resultou na minha dissertação, fui convidada para um baile de forró onde costumam ir algumas freguesas do Flôr do André, localizado na rua Riachuelo, a três quadras do bar. Elas gostam desse lugar porque "mulher não paga entrada", "a cerveja é baratinha" $e$ "ninguém enche o saco"12, além de ficar na área onde elas moram. Perto de uma hora da manhã, saímos do Flôr do André - Joana, Magnata, Luciana, Bety, Edna, Raquel, Maisa,

\footnotetext{
${ }^{12} \mathrm{~A}$ fala se refere à tranqüilidade de dançar entre elas sem que os homens sejam muito insistentes em tentar dançar com alguma do grupo. Isto não implica que não aceitem às vezes dançar com homens.
} 
Jô e eu - rumo ao forró. Aceitei não só para ver como atuavam fora do bar, mas para continuar a conversar com Edna, uma mulher de uns 50 anos, antiga freqüentadora do bar que só vai durante os fins de semana, quando deixa sua mulher em casa e sai sozinha. ${ }^{13}$ Sua estética, sem se afastar muito da de várias outras freguesas do lugar, embodificava o aspecto masculino comumente estereotipado: cabelo bem curto, quase raspado dos lados, ao estilo militar, camiseta ampla com mangas curtas e de cores escuras (azul marinho e cinza) que invisibilizava as linhas do seu torso, bermudas largas de algodão, de uma cor verde azeitonada, cuidadosamente passada e sapatos náuticos de couro marrom. $\mathrm{O}$ perfume de homem e uma pochete preta acompanhavam a indumentária que se completava com a ausência de maquiagem e movimentos endurecidos do corpo, dos braços.

Já no lugar, Raquel e Edna, ambas sozinhas nesta noite, se ofereceram para me ensinar a dançar forró. Foi Raquel quem tomou a iniciativa. Dancei com ela umas poucas músicas até que Edna se aproximou de nós - "Vem cá argentina, vamos dançar" -, tomando-me cortesmente pela mão, levou-me até a pista. Começamos a dançar. Edna ocupando o lugar do homem e eu da mulher. Com isto quero dizer que, com relação ao resto das duplas de baile do lugar, ela me tomava do mesmo jeito que os homens tomavam as mulheres: uma mão dela detrás da minha cintura e a minha, em cima do seu ombro, as outras entrelaçadas $e$ os corpos quase pregados. Porém, o quase não se cumpria no nosso caso: com a mão que abraçava minha cintura, Edna apertava meu corpo contra o dela para que eu aprendesse os movimentos. Isso não me incomodava tanto porque ela continuava a ser a correção personificada; entretanto, a posição da sua pochete começou a me parecer esquisita. Quando duas

${ }^{13}$ Segundo ela, "tem mulher" há quinze anos. Moram no mesmo prédio, mas em apartamentos separados porque "não vou agüentar o filho dela o tempo todo. Quando a gente quer estar junta, ela vem pra casa; depois, que ela volte com o filhote. Eu não quero crianças por perto". 
De entendidas e sapatonas

mulheres dançam coladas, como era o caso, não existe uma protuberância sobressaindo de nenhum dos dois corpos; mesmo com as pernas entrelaçadas, não existe uma exterioridade volumosa, onipresente, salientando da calça. Mas, neste caso, a pochete colocada no lugar certo ocupava o espaço dessa protuberância de modo tal que roçava contra minha virilha apesar dos quinze centímetros a mais de altura que me diferenciam de Edna. O que eu estava sentindo não parecia tanto uma pochete quanto uma mala. Incômoda como me sentia, pedi para ela mudar para um dos lados do quadril a localização do artefato. Ela me olhou e, respondendo "esse é o lugar certo", apertou-me mais ainda e continuou dançando enquanto me ensinava a dançar forró. Vulto, perfume de homem, postura rígida, seriedade, cortesia e a impossibilidade de mudar os planos de "quem leva" $e$ "quem é levad@" emolduravam o quadro que tinha a pochete como ponto de luz e centro da perspectiva.

Foi nesse momento que aquela enunciação que eu conhecera anos atrás voltou. Mesmo sendo a minha mente quem lembrara, foi o meu corpo quem compreendeu empaticamente o significado profundo da expressão. Visto desse modo, a pochete exterioriza a genitália, colocando-a numa situação corporal similar àquela dos homens. Aquilo que fazia-me sentir desconfortável era o fato de reviver na dança com uma mulher, uma sensação corporal que só reconhecia (e evitava) na hora de dançar com os homens. A suposta "igualdade" espelhada entre corpos que recria a mais romântica e ativista ${ }^{14}$ das formas do amor lésbico, caía por terra empurrada por uma pochete colocada "no lugar certo".

${ }^{14}$ Existe em certos discursos do ativismo lesbo-feminista a idéia de que o amor lésbico está regido pelos signos da simetria e da igualdade manifestos na suposta ausência de papéis ativos e passivos nos relacionamentos erótico-afetivos. Este fato é utilizado para marcar a diferença com o sexo heterossexual ou gay, no qual alguém penetra ou alguém é penetrado. Acho necessário assinalar que esses discursos excluem deste ideal outras formas de relacionamentos entre mulheres, onde a igualdade não é o objetivo, como, por exemplo, nas relações butchfemme (hipermasculinas com hiperfemininas) consideradas, por esse mesmo ativismo, como politicamente incorretas. 
Andrea Lacombe

Sem reificar os espaços em que se desenvolvem os gêneros, este exemplo me permitiu pensar na idéia de uma masculinidade que não se atrela a um só corpo, mas salta de um a outro. A pochete poderia ser pensada como uma estratégia desestabilizadora do processo de construção que opera através da reiteração de normas, mecanismo mediante o qual o sexo se produz e reproduz; quer dizer, como uma estratégia de desconstrução dessa norma, dando lugar a uma masculinidade sem pau, mas com dispositivos performáticos que o substituem $e$ ressignificam para além de sua função reprodutiva ou penetradora. De que outra forma poderia nomear essas atuações em que o corpo extrapola os limites dados pela pele e recorre a outros elementos para redefinir a identificação socialmente atribuída? Nas palavras de Dona Haraway (1995), por que deveriam nossos corpos finalizar na pele?

A definição platônica do simulacro (Jameson apud Haraway, 1995:264) é "a cópia da qual não existe original". Pensada desse modo, a masculinidade das entendidas do Flôr do André bem poderia ser formulada como simulacro: o homem não é o original, a mulher também não; o que resulta não é uma mistura invertida de ambos, mas uma disposição diferente não remissível aos moldes. Do mesmo modo, um simulacro de desastre aéreo praticado em um hospital de emergência de uma cidade onde nunca houve um acidente de tais magnitudes não pode ser pensado como remissível a um molde, mesmo que seja orientado por um manual de desastres, porque a atuação do corpo sanitário do lugar se limita a uma performance do nada, fora da experiência. Simular uma experiência se diferencia de copiá-la na medida em que a cópia se faz sobre um evento já realizado e o simulacro responde a fatos para os quais aqueles que o efetuam não têm antecedentes.

Paragonando a argumentação que Butler (2000:87-113) produz para explicar o porquê da falsidade de pensar a 
De entendidas e sapatonas

homossexualidade como cópia da heterossexualidade ${ }^{15}$, podemos alegar quanto à invalidez da remissão das díades homemmasculinidade e mulher-feminidade a moldes a priori para logo visualizar como cópias misturadas de ambos - a masculinidade de mulheres, a feminidade dos homens, as hipermasculinidades gays (dos ursos) ${ }^{16} e$ as hiperfeminidades lésbicas (das femmes) $)^{17}$ ou, em um patamar extremo, os transgêneros (tanto de mulher a homem como de homem a mulher). Se a sexualidade se imprime na matéria (nos corpos) através da atuação que sua vivência implica, se sexo e gênero não aparecem como naturais, mas como categorias historicamente construídas, a explosão das categorias e os modos de performatizar e vivenciar a sexualidade perde-se no infinito da imaginação.

\footnotetext{
${ }^{15}$ Segundo Butler, o termo homossexualidade é concebido com anterioridade o de heterossexualidade, que só aparece como contrapartida do primeiro termo (já que a heterossexualidade é pensada como natural e não precisa ser nomeada). Assim, "sin la homosexualidad como copia, no habría una construcción de la heterosexualidad como origen. Esta presupone en este caso a aquella. Si el homosexual como copia precede al heterosexual como origen, parece razonable conceder que la copia viene antes que el origen, que la homosexualidad es el origen y la heterosexualidad, la copia. Pero estas simples inversiones no son realmente posibles (...) toda la estructura de la copia y el origen se revela como extremadamente inestable ya que cada posición se invierte en la otra y confunde la posibilidad de una forma estable que localice la prioridad lógica o temporal de cada término. (...) Si la heterosexualidad es una imposible imitación de sí misma, que se constituye de un modo performativo como el original, entonces su parodia imitativa - cuando y donde existen en las culturas gays - es solamente una imitación de una imitación, una copia de una copia pues no hay original" (Butler, 2000:100-101).

${ }^{16}$ Os autodenominados "ursos" são homens gays de aspecto rude $e$ aparentemente descuidado, de contextura física forte e muito pêlo no corpo que não respondem aos cânones estéticos do corpo malhado e definido. "El modelo urso es un hombre no muy arreglado, por lo menos no afectado ni muy preocupado com su apariencia física ni visual" (Figari, 2003:362).

${ }^{17}$ As femme, por sua vez, são as lésbicas cuja estética é hiperfeminina: minissaias, salto alto, lábios pintados, muita maquiagem e modos suaves. Mesmo que sejam historicamente associadas às parceiras das butchs, não necessariamente se interessam só por elas.
} 
Desse modo, uma performance corporal masculina não tem como correlato direto a sexualidade masculina. Assim, a performance constitui o sujeito que se expressa através da repetição dela. $\mathrm{O}$ fato de ter um aspecto masculino não implica o uso de instrumentos penetrantes na hora dos relacionamentos sexuais. Na cama, o pênis fica pendurado numa cadeira junto com a calça e a pochete: "as butchs alternam entre a masculinidade nas ruas e a feminidade nos lençóis". ${ }^{18}$ Com a pochete convertida em um falo lesbiano (nos termos butlerianos), quer dizer, o fato de ter e ser o falo, a lógica estrutural que divide homens e mulheres como aqueles que respectivamente têm e são o falo se desestabiliza como "lógica de no contradicción en la que se basa la idea de que tiene que ser uma cosa o la otra, propia del intercambio heterosexual normativo" (Butler, 2002:139). Desse modo, a pochete instrumentaliza-se como um ter que existe em relação a um ser que é, por sua vez, parte do seu próprio efeito significante.

La posición fantasmática del hecho de "tener" se rediseña, se hace transferible, sustituible, plástica; y el erotismo producido dentro de este tipo de intercambio depende tanto del desplazamiento desde los contextos masculinistas tradicionales como del redespliegue crítico de sus figuras centrales de poder. (Id. ib.:169)

Ou seja, uma espécie de contra-sexualidade ${ }^{19}$, onde a divisão freudiana se desmancha frente à reinvenção performática de um

\footnotetext{
18 "butchs switch between being masculine on the streets and female in the sheets" (Halberstam, 1998:125).

${ }^{19}$ Referência ao "Manifesto contra-sexual" de Beatriz Preciado onde a autora contrapõe "contra-sexualidade" a hetero e homossexualidade em uma tentativa de reinvenção das práticas sexuais além da discursividade médica moderna. $\mathrm{O}$ que Preciado quer explicitar são outros modos de vivenciar a sexualidade e a busca do prazer (basicamente lésbica) onde o corpo todo se converte em objeto penetrador (mãos, pés, língua, peitos) e penetrado (tanto a vagina quanto o ânus e a boca ganham o mesmo status). Entretanto, ela considera os brinquedos
} 
De entendidas e sapatonas

falo sem pau que elimina a necessidade da preexistência da heterossexualidade para pensar a masculinidade.

Nas conversas sobre sexo com as freguesas do Flôr do André, apareceu uma vez, e por parte de uma pessoa só, o uso de consolos $^{20}$ durante $\mathrm{o}$ ato sexual. $\mathrm{O}$ resto delas se manifestou contra brinquedos que tivessem aparência de genitália masculina ou a genitália masculina propriamente dita: "eu, pra minha mulher, só tenho dedos e língua", "aqui [assinalando a vagina] nunca entrou pau nem coisa parecida! eu só gosto de corpo de mulher se esfregando contra o meu", "o segredo tá mesmo é no toque, nas mãos", foram algumas das expressões que escutei no lugar vindas às vezes daquelas mulheres mais masculinas que até se orgulhavam de usar cueca. Nas palavras de Cornwall \& Lindisfarne (1994:38),

a identidade da lésbica butch não representa uma identidade masculina superimposta ou uma feminidade descontextualizada, mas a desestabilização do modo em que ambos os termos se apresentam no jogo erótico. ${ }^{21}$

O que as freguesas do Flôr do André deixam a descoberto é a fragilidade das assertóricas categorias de masculino-feminino $e$ homem-mulher, desestabilizando sua pretendida universalidade:

gênero feminino (feminidade) e gênero masculino (masculinidade) não são, em última instância, considerados como exclusividade dos corpos sexuados masculinos e

sexuais (dildos) como uma extensão do corpo além da pele que devem ser incorporados ao jogo sexual com esse significado. Assim, ela desestabiliza o estatuto do pênis tirando dele a exclusividade como único objeto penetrador. Cf. Preciado, 2002.

${ }^{20}$ Nome dado a um tipo de brinquedo sexual em forma de pênis (ou similar) conhecido também pela palavra inglesa dildo.

21 "the lesbian butch's sexual identity represents not just a superimposed masculine identity or merely a decontextualized female body but the destabilization of both terms as they come into erotic interplay". 
Andrea Lacombe

femininos, respectivamente. A percepção popular pode unir irredutivelmente, sexo, gênero e sexualidade, mas trata-se de uma união assimétrica e não de uma condição fixa ou permanente. ${ }^{22}$

O fato não é a desaparição das categorias, mas a reinvenção do significado que se consegue simplesmente habitando-as, negociando os espaços através das práticas e diluindo as fronteiras que separam feminino de masculino, mulher de homem ou, em termos mais abrangentes, natureza de cultura.

Como considerar uma imagem de mulher que, sem se pensar homem, extrapola os limites estabelecidos para "ser mulher"? Mulheres que usam cueca, tocam a virilha para acomodar uma imaginária "mala" 23 , utilizam espaços socialmente reservados aos homens; entretanto, se maquiam, levam a sério a combinação de cores, fazem dieta para não ter barriga no verão $e$ mantêm axilas, pernas e buço perfeitamente depilados durante o ano inteiro.

Pensar em mulheres masculinas não implica necessariamente aplicar uma "inversão" dos papéis genéricos; significa uma nova volta do parafuso: estabelecer modos alternativos de masculinidade que não estejam necessariamente inscritos em um corpo social e biológico de homem ou, de outro

22 "female gender (feminity) and male gender (masculinity) are not ultimately regarded as the exclusive province of female and male sexed bodies, respect. Sex, gender and sexuality may be populary perceived as irreducibly joinend but this remanins asimetrical and not a permanently fixed condition" (Robertson, 1999:8).

${ }^{23}$ Em diálogo com meu amigo e sociólogo Carlos Fígari, conheci esta palavra como modo popular carioca (muito difundido na fala dos gays) de se referir à saliência que se entrevê através da calça ou da sunga dos homens em que justamente só é possível distinguir o contorno formado pelo pênis e os testículos. Do mesmo modo, em uma "mala" só é possível considerar o tamanho externo do conjunto; um vulto que não permite enxergar as singularidades que há dentro. Na definição de "mala" do Dicionário Aurélio Eletrónico, versão 3.0, aparece também como uma acepção: "Bras. Chulo Os órgãos genitais masculinos". 
De entendidas e sapatonas

lado, modos de ser mulher que não correspondam àqueles estipulados como papéis femininos. Nas palavras de Judith Butler,

si cuestionamos el carácter fijo de la ley estructuralista que divide y limita los "sexos" en virtud de su diferenciación diádica dentro de la matriz heterosexual, lo haremos desde las regiones exteriores de esa frontera (no desde una "posición", sino desde las posibilidades discursivas que ofrece el exterior constitutivo de las posiciones hegemónicas) y ese cuestionamiento constituirá el retorno desbaratador de los excluidos desde el interior de la lógica misma del simbolismo heterosexual (Butler, 2002:33).

\section{Referências bibliográficas}

BLÁZQUEZ, Gustavo. Coreografias do gênero: Uma etnografia dos bailes de cuarteto. (Córdoba, Argentina). Tese de Doutorado em Antropologia Social, PPGAS-MN-UFRJ, Rio de Janeiro, 2004.

BUTLER, Judith. Cuerpos que importan - Sobre los límites materiales y discursivos del sexo. Buenos Aires, Paidós Editores, 2002.

. Imitación e insubordinación de género. In: Grafías de Eros. Historia, género e identidades sexuales. Buenos Aires, Edelp, 2000.

CORNWALL, Andrea \& LindisfaRne, Nancy. Introduction e "Gender Power and anthropology. In: CORNWALL, A. \& LindisfarNe, N. (eds.) Dislocating masculinity. Londres, Routledge, 1994.

FIGARI, Carlos Eduardo. L@s otr@s cariocas: interpelaciones, experiencias e identidades homoeróticas en Rio de Janeiro (Siglos XVII al XX). Tese de doutorado em Sociologia, IUPERJ, Rio de Janeiro, 2003.

FRY, Peter e MACRAE, Edward. O que é homossexualidade. São Paulo, Abril Cultural/Editora Brasiliense, 1985.

HAlberstam, Judith. Female masculinity. Durham and London, Duke University Press, 1998.

HaRaWAY, Donna J. Ciencia, cyborgs y mujeres - La reinvención de la naturaleza. Madrid, Ediciones Cátedra, 1995. 
INGOLD, Tim. The art of translation in a continuous world. In: PÁLSON, Gísli. (ed.) Beyond boundaries: undestanding, translation and anthropological discourse. Oxford/Providence, Berg, 1993.

LACOMBE, Andrea. "Pra homem já tô eu": Masculinidades e socialização lésbica em um bar no centro do Rio de Janeiro. Dissertação de Mestrado, PPGAS-MN, Rio de Janeiro, 2005.

MACHADO DA SILVA, Luiz António. O Significado do Botequim. Revista América Latina, nº 12 (3), jul-set 1969.

Muniz De OliveIRA, Jacqueline. Mulher com mulher dá jacaré, uma abordagem antropológica da homossexualidade feminina. Dissertação de Mestrado em Antropologia Social, PPGAS-MNUFRJ, Rio de Janeiro, 1992.

PRECIADO, Beatriz. Multitudes queer: notes pour un politique des "anormeaux". Multitudes, n 12, printempts, 2003.

El manifiesto contrasexual. Madrid, Opera Prima, 2002.

ROBERTSON, Jenifer. Dying to tell: sexuality and suicide in Imperial Japan. Signs. Journal of women in culture and society, vol. 25, $\mathrm{n}^{\circ}$ 1, The University of Chicago Press, 1999.

SEDGWICK KOSOFSKY, E. Between men: English literature and male homosocial desire. New York, Columbia University Press, 1985.

VALE DE ALMEIDA, Miguel. Senhores de si. Uma interpretação antropológica da masculinidade. Lisboa, Fim de Século Editora, 1995. 